\title{
Transferrinfection: A Highly Efficient Way to Express Gene Constructs in Eukaryotic Cells
}

\author{
KURT ZATLOUKAL, ERNST WAGNER, \\ MATT COTTEN, STEPHEN PHILLIPS, \\ CHRISTIAN PLANK, PETER STEINLEIN, \\ DAVID T. CURIEL, ${ }^{a}$ AND MAX L. BIRNSTIEL \\ Research Institute of Molecular Pathology \\ Dr. Bohr-Gasse 7 \\ A-1030 Vienna, Austria \\ "University of North Carolina at Chapel Hill \\ CB\#7020, 724 Burnett-Womack Building \\ Chapel Hill, North Carolina 27599-7020
}

The expression of antisense RNA is a powerful means of extinguishing unwanted gene activity in the eukaryotic cell (see this volume). This approach has worked particularly well in plants ${ }^{1-4}$ and animals 5 in which antisense-producing gene constructs can be inserted into the germ cell. In man, germ cell manipulation is not yet possible. The problem arises as to how somatic cells can be targeted with genes generating antisense RNAs.

Apart from retroviral vectors, a multitude of techniques exist for introducing DNA into eukaryotic somatic cells (ref. 6 and references therein). During the last few years, we and others ${ }^{7,8}$ have been interested in adapting the cellular mechanisms of receptor-mediated endocytosis of macromolecules for the importation of DNA molecules into cells. ${ }^{9-11}$ The principle of the method is to covalently connect a polycation, usually polylysine, to a ligand for a receptor on the cell surface. DNA, usually in the form of cloned genes, is then bound ionically to the polylysine. During importation of the DNA by receptor-mediated endocytosis the ligand binds to the receptor, and during internalization of both of these entities the DNA is thought to become colocalized, first in the coated pits and later in the endosome. The further fate of the DNA can be particularly well studied when reporter genes such as the firefly luciferase gene or the bacterial $\beta$-galactosidase gene, driven from a viral enhancer/promoter, are employed.

It can be predicted that DNA in the endosome is directed to the lysosomal compartment, where it can be expected to be destroyed by resident nucleases. Despite this, apparently a small amount of DNA does escape destruction, so that reporter gene activity is observed in a few cells of a cell population (see below). Because the genes are expressed, it is probably safe to assume that some of the DNA has reached the cell nucleus. When transferrin is used as a ligand, the transfection procedure is called "transferrinfection."

Consistent with the postulated chain of events during transferrinfection, we find that the addition of the lysosomatropic agent chloroquine, which prevents acidification and concomitant activation of lysosomal degradative enzymes, greatly enhances expression of the chosen reporter gene. ${ }^{11}$ This enhancement can be spectacular, as for instance in the human erythroleukemic cell line $\mathrm{K} 562$ in which subsequent to the 
addition of chloroquine, virtually $100 \%$ of the cells express the reporter gene for up to 10 days at a very high level. ${ }^{6}$ The reason for the great ease with which K562 cells can be transfected can be correlated with a particular physiological feature of K562 cells. The very high level of gene expression in these cells is probably due to the absence of the $\mathrm{Na}^{+}, \mathrm{K}^{+}$-ATPase regulation of endosomal acidification in these cells. In $\mathrm{K} 562$ cells the $\mathrm{pH}$ of the endosomal compartment reaches unusually low values, ${ }^{12}$ and consequently the endosomal compartment is expected to accumulate exceptionally high amounts of chloroquine which can be expected to act osmotically, vacuolarizing and finally disrupting the endosome (R. F. Murphy, personal communication) and thus releasing the DNA from endosomal confinement. These findings and hypotheses suggest that the rate-limiting step for reporter gene expression during transferrinfection lies at the level of the endosome and that to obtain high levels of gene expression, strategies need to be developed that allow exit of the DNA from the endosome into the cytoplasmic compartment.

Many viruses enter cells via the endosomal route but escape destruction in the lysosome owing to their molecular design which allows them to exit from the endosomes by disrupting the endosomal membranes at low $\mathrm{pH} \cdot{ }^{13}$ This endosomolytic property of the virus is a feature of the proteinacious capsid and is not dependent on viral gene activity during endosomolysis. From this it can be predicted that after inclusion of such viruses, for instance adenovirus, during receptor-mediated endocytosis, the viruses will bind to viral receptors and will become colocalized in the endosome together with the DNA/polylysine-ligand conjugates (FIG. 1). Because of the disruption of the endosome by the virus, the DNA complexes may be released into the cytoplasm and obtain access to the nuclear compartment. Indeed, it is found experimentally that the inclusion of virus during transferrinfection greatly enhances gene expression, by a factor of as much as 1,000 , for cells that have both virus and transferrin receptors. ${ }^{14}$ As the endosomolytic function of the virus resides in the capsid proteins, the use of genetically ${ }^{15}$ or biochemically ${ }^{16}$ inactivated virus minimizes the danger of viral infection while providing the membrane-disrupting function of the virus.

Although the addition of adenovirus can enhance transferrinfection by a large factor, ${ }^{14}$ the strategy still suffers from the drawback that relatively high levels of virus are required to ensure colocalization of virus and DNA/polylysine-transferrin binary complexes in the same endosome. Furthermore, viral enhancement is only possible for those cells that express adenoviral receptors on their surface. These difficulties can be circumvented by a physical linkage between the adenovirus and the polylysinetransferrin/DNA complex. Such a link is afforded, for instance, by covalently linking polylysine with an antibody $(\mathrm{Ab})$ that is directed against an epitope of the viral adeno capsid proteins. ${ }^{17}$

We now report on two new kinds of ternary complexes in which the link between adenovirus and polylysine is established by covalently linking the two entities by means of transglutaminase. ${ }^{18,19}$ Transglutaminase catalyzes the formation of epsilon(gamma-glutamyl)lysine bonds between glutamines of the viral capsid proteins and the epsilon-amino groups of the polylysine. In an alternative protocol we biotinylated adenovirus and established a link with streptavidinylated polylysine. A "combi" complex can be generated by adding, first, a limited amount of virus-polylysine to a given amount of DNA, neutralizing only a fraction of the negative charges of the DNA, and then adding polylysine-transferrin conjugate to the complex, neutralizing the remainder of the charges. Such a ternary complex containing adenoviruspolylysine/polylysine-transferrin and DNA has in theory the capacity to enter the eukaryotic cell by means of either the adenovirus receptor or the transferrin receptor (FIG. 2). Once internalized within the endosome, the endosomolytic property of the 

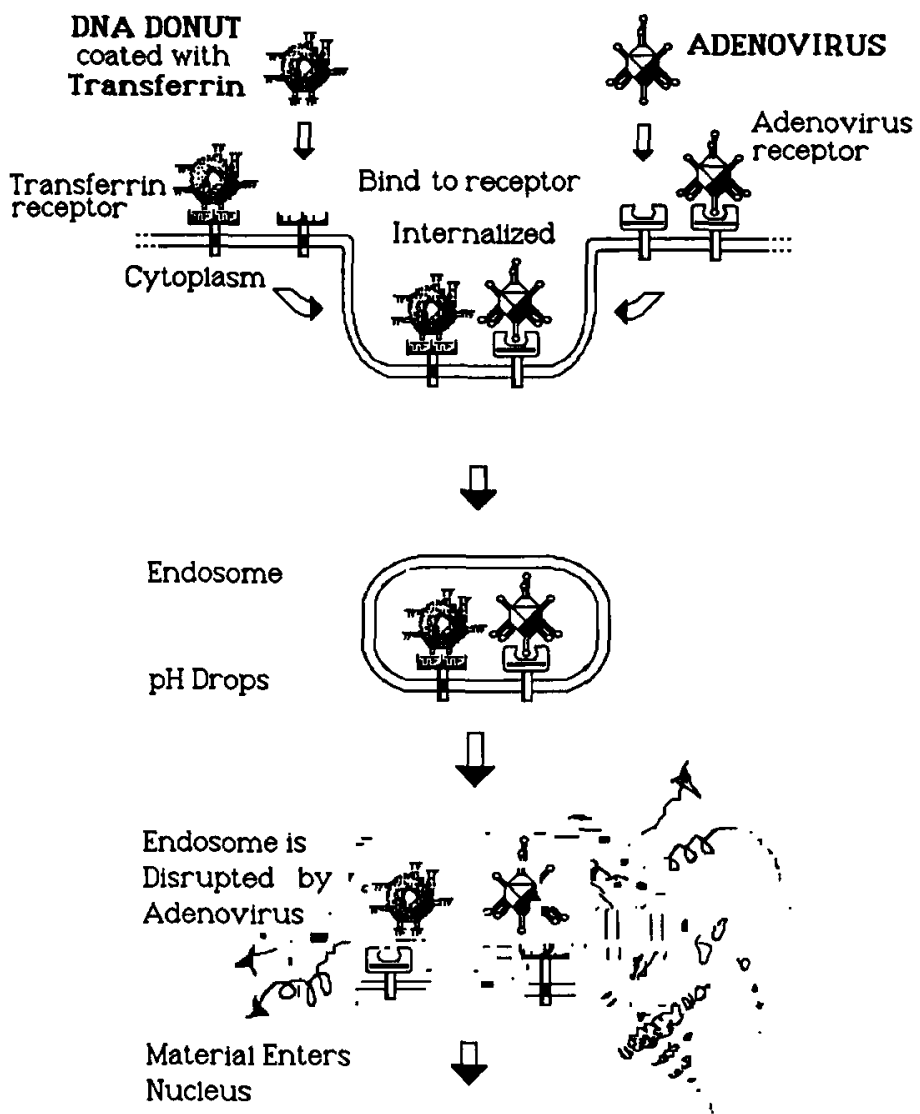

FIGURE 1. Cartoon of adenovirus-enhanced transferrinfection. The adenovirus in many instances is thought to become colocalized with the DNA conjugate which interacts with the transferrin receptor. As adenovirus disrupts the endosome, the DNA exits to the cytoplasm.

conjugated virus will be exploited, and the DNA will gain access to the cytoplasm. A short report of these results has been published previously. ${ }^{18}$

\section{MATERIALS AND METHODS}

Human transferrin-polylysine conjugates were obtained from Serva (Heidelberg, Germany).

\section{Preparation of Fusogenic Peptide-Polylysine Conjugate}

The influenza peptide ("Influ") of the sequence Gly-Leu-Phe-Gly-Ala-Ile-AlaGly-Phe-Ile-Glu-Asn-Gly-Trp-Glu-Gly-Met-Ile-Asp-Gl y-Gly-Gly-Cys (compare ref. 20) was synthesized by the Fmoc-procedure 22 on SASRIN resin (Bachem) using an 
Applied Biosystems 431A peptide synthesizer. The side-chain protecting groups were $t$-butyl- for Cys, Glu, and Asp and trityl- for Asn. Coupling was monitored by a ninhydrin test which showed $>98 \%$ coupling efficiency for each step. Beginning with amino acid 19, double couplings were carried out. Cleavage from solid support and removal of most protective groups were performed with trifluoroacetic acid and various scavengers according to standard procedures. ${ }^{23}$ The crude product obtained, still containing the cysteine in $t$-butyl protected form, was purified by reverse phase HPLC (BIORAD Hi-Pore RP-304 column; buffer A: $20 \mathrm{mM}$ aqueous $\mathrm{NH}_{4} \mathrm{HCO}_{3}+300 \mu \mathrm{l} 25 \% \mathrm{NH}_{3} /$; buffer $\mathrm{B}: \mathrm{A}$ in $98 \%$ methanol, gradient elution

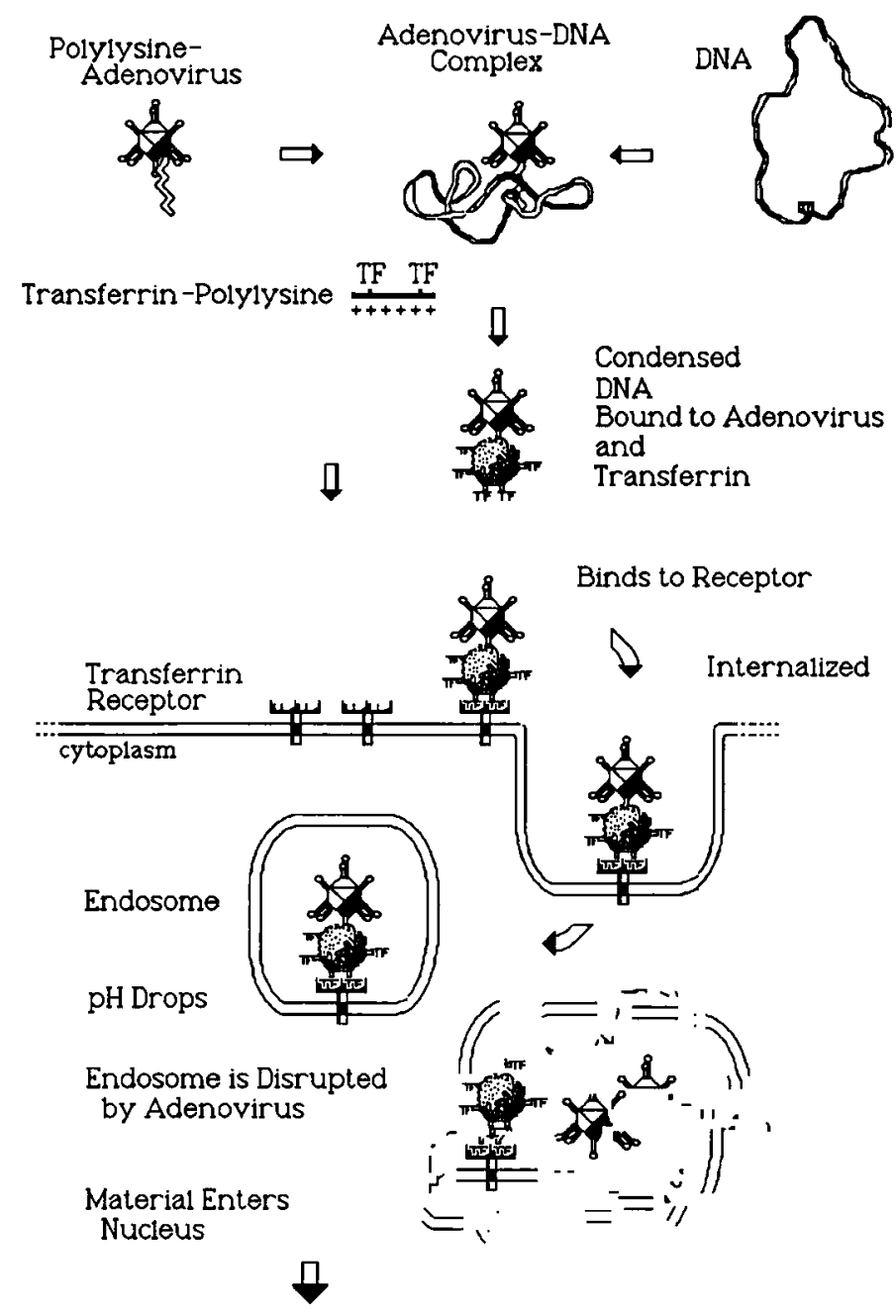

FIGURE 2. Cartoon of linked virus-enhanced transferrinfection. Colocalization of the endosomolytic virus and the transferrin receptor complex is assured even at low input of adenovirus. As only the capsid function of the virus is exploited, the viral genome can be inactivated without loss of endosomolytic activity of the virus. 
$50-100 \%$ buffer B). The pure, $t$-butyl protected peptide was eluted at $80 \% \mathrm{~B}$ and converted to the free mercapto form by treatment with thioanisol/ethanedithiol/ trifluoroacetic acid/trifluoro-methanesulfonic acid (2/1/40/3). The deprotected peptide was isolated by precipitation with ether and subsequent gel filtration (Sephadex G-25) under an argon atmosphere. This influenza peptide was conjugated to pyridyldithiopropionate-modified polylysine pLys $_{300}$ (prepared as described in ref. 9) via disulfide bond formation. Conjugates were isolated by cation-exchange chromatography on a Mono S HR/5/column (Pharmacia) using a gradient from $20 \%$ to $100 \%$ B; (A: $20 \mathrm{mM}$ HEPES, pH 7.3; B: $20 \mathrm{mM}$ HEPES, pH 7.3, $3 \mathrm{M}$ sodium chloride). The main product fraction, eluting with $1.5 \mathrm{M}$ sodium chloride, was pooled and dialyzed twice against $\mathrm{HBS}(150 \mathrm{mM} \mathrm{NaCl}, 20 \mathrm{mM}$ HEPES, $\mathrm{pH} 7.3)$ to yield, according to a ninhydrin assay and absorption at $280 \mathrm{~nm}$, conjugates ("InflupL") with a molar ratio of peptide:polylysine of $4: 1$.

\section{Adenovirus Preparation}

The adenovirus strain d 312 described by Jones and Shenk ${ }^{15}$ with a deletion in the E1a region was used. Replication of the virus was carried out in E1a-transcomplementing cell line 293 , and purification was carried out on a large scale as described by Davidson and Hassell. ${ }^{24}$ The purified virus was diluted with an equal volume of glycerol, and aliquots were stored at $-70^{\circ} \mathrm{C}$. The virion concentration was determined by UV-spectrophotometric analysis of the extracted viral genomic DNA (conversion factor: one optical density unit $\left[\mathrm{OD}, \mathrm{A}_{260}\right]$ corresponds to $10^{12}$ viral particles/mi). ${ }^{25}$

\section{Biotinylation of Adenovirus dl312}

Two milliliters of a gel-filtered (Sephadex G-25 PD10, Pharmacia) solution of adenovirus dl312 (about $10^{11}$ particles per $\mathrm{ml}$ ) in $150 \mathrm{mM} \mathrm{NaCl}, 5 \mathrm{mM}$ HEPES, pH $7.9 / 10 \%$ glycerol, was mixed with $10 \mu \mathrm{l}(10 \mathrm{nmol})$ of a $1 \mathrm{mM}$ solution of NHS-LC biotin (Pierce 21335). After 3 hours at ambient temperature the biotin-modified virus was separated from the excess reagent by gel filtration on Sephadex G-25 in 150 $\mathrm{mM} \mathrm{NaCl}, 5 \mathrm{mM}$ HEPES, $\mathrm{pH} \mathrm{7.9/40 \%} \mathrm{glycerol} \mathrm{(total} \mathrm{volume} 2.2 \mathrm{ml}$ ) and stored at $-70^{\circ} \mathrm{C}$. Biotinylation of the virus was demonstrated by qualitative detection after the dropwise addition of various dilutions onto a nitrocellulose membrane. After drying at $80^{\circ} \mathrm{C}$ for 2 hours in a vacuum dryer, blocking with BSA, incubating with streptavidinconjugated alkaline phosphatase (BRL), washing, and incubating for 1 hour with the developing solution NBT/X-phosphate (nitro-blue-tetrazolium salt/5-bromo-4chloro-3-indolylphosphate, toluidine salt; Boehringer Mannheim), a positive color reaction showed that it had been biotinylated.

\section{Preparation of Streptavidin-Polylysine Conjugates}

The coupling of streptavidin to polylysine was effected using the method described by Wagner et al. ${ }^{9}$

Seventy-nine $\mathrm{nmol}(4.7 \mathrm{mg})$ of streptavidin in $1 \mathrm{ml}$ of $200 \mathrm{mM}$ HEPES, $\mathrm{pH} 7.9$, and $300 \mathrm{mM} \mathrm{NaCl}$ were treated with a $15-\mathrm{mM}$ ethanolic solution of SPDP (236 $\mathrm{nmol}$ ). After 1.5 hours at ambient temperature the modified protein was gel filtered over a Sephadex G-25 column, yielding $75 \mathrm{nmol}$ of streptavidin modified with 196 
nmol of dithiopyridine linker. The modified protein was reacted under an argon atmosphere with 3-mercaptopropionate-modified polylysine $(75 \mathrm{nmol}$, average chainlength 290 lysine monomers, modified with $190 \mathrm{nmol}$ mercaptopropionate linker) in $2.6 \mathrm{ml}$ of $100 \mathrm{mM}$ HEPES, $\mathrm{pH} 7.9$, and $150 \mathrm{mM} \mathrm{NaCl}$. Conjugates were isolated by cation exchange chromatography on a Mono S HR/5/column (Pharmacia) (gradient: $20-100 \%$ buffer $B$, buffer ( $A$ and $B$, see above)). The product fraction eluted at a salt concentration of between 1.2 and 1.7 M. Dialysis against HBS (20 mM HEPES,

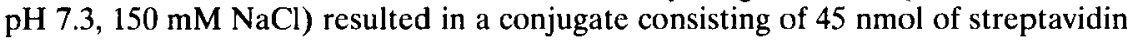
and $53 \mathrm{nmol}$ of polylysine (Strept-pL).

\section{Enzymatic Linkage of Adenovirus dl312 and Polylysine}

Two milliliters of the adenovirus preparation (strain dl312;5 $\times 10^{10} \mathrm{PFU} / \mathrm{ml}$ ) were applied to a Sephadex G-25 gel filtration column (Pharmacia) equilibrated with $25 \mathrm{ml}$ of reaction buffer $(0.1 \mathrm{M}$ Tris- $\mathrm{HCl}$; $\mathrm{pH} 8.0,2 \mathrm{mM}$ DTT, $30 \%$ glycerol $)$. Elution was carried out with $3.5 \mathrm{ml}$ of reaction buffer. The reaction mixture for enzymatic coupling consisted of $1,150 \mu \mathrm{l}$ of the virus elution fraction, $0.5 \mathrm{nmol}$ guinea pig liver transglutaminase (Sigma), 2 or $20 \mathrm{nmol}$ of polylysine $290,10 \mathrm{mM} \mathrm{CaCl}_{2}$ and reaction buffer in a final volume of $1,500 \mu \mathrm{l}$. The reaction was carried out at $37^{\circ} \mathrm{C}$ for 1 hour and then stopped by the addition of $30 \mu \mathrm{l}$ of $0.5 \mathrm{M}$ EDTA. To monitor the specificity of the coupling, reaction mixtures were also prepared without transglutaminase. Nonincorporated polylysine was separated from the viruses by centrifugation in a $\mathrm{CsCl}$ gradient (density $1.33 \mathrm{~g} / \mathrm{ml} ; 170,000 \times \mathrm{g}, 2$ hours). The fraction containing the viruses was collected, mixed with an equal volume of glycerol, frozen in liquid nitrogen, and stored at $-70^{\circ} \mathrm{C}$.

To demonstrate that polylysine and adenovirus were covalently coupled, the reaction was carried out as described with polylysine that had been labeled with ${ }^{125}$ I by means of Bolton-Hunter reagent (Amersham). After CsCl-gradient centrifugation the virus fraction was drawn off and separated by means of another $\mathrm{CsCl}$ gradient. The gradient was then fractionated, and the radioactivity in every fraction was determined using a scintillation counter. It became apparent that radioactive polylysine had accumulated in the virus fraction. In the control mixture without transglutaminase there was no accumulation of radioactive polylysine in the virus fraction.

\section{Formation of the Binary Complexes of Virus-Polylysine /DNA}

Forty $\mu$ l of the biotin-modified virus fraction (ca. $3 \times 10^{9}$ viral particles) were mixed with $800 \mathrm{ng}$ Strept-pL in $160 \mu \mathrm{l} \mathrm{HBS}$. After 30 minutes, $6 \mu \mathrm{g}$ of the DNA plasmid pCMV-L (reporter gene construct containing the Photinus pyralis luciferase gene under the control of the cytomegalovirus promoter) in $160 \mu \mathrm{l} \mathrm{HBS}$ were added and incubated for 30 minutes at ambient temperature. For full condensation of the DNA, $3 \mu \mathrm{g}$ polylysine 290 in $160 \mu$ l HBS was added, and after further incubation at ambient temperature, the binary complexes were applied to tissue culture cells.

\section{Formation of Ternary Complexes of Virus-Polylysine/Polylysine-Transferrin/DNA}

Forty $\mu$ l of biotinylated viruses were mixed with Strept-pL and DNA as above. Then DNA was condensed by the addition of $9 \mu \mathrm{g}$ human transferrin-polylysine 
(hTfpL) to the mixture, incubation was continued for a further 30 minutes, and finally the ternary complexes were applied to tissue culture cells. Alternatively, $50 \mu \mathrm{l}$ of the enzymatically polylysine-modified viruses (ca. $4 \times 10^{8}$ viral particles) were complexed to $6 \mu \mathrm{g}$ of DNA in $30 \mu \mathrm{l}$ HBS by incubation for 30 minutes. Full condensation of DNA was achieved by the addition of $8 \mu \mathrm{g}$ of murine transferrinpolylysine 290 (mTfpL 290).

\section{Transfection of HeLa Cells and Mouse Hepatocytes with a B-Galactosidase Reporter Gene-Construct and in situ Demonstration of $\beta$-Galactosidase Expression}

HeLa cells and mouse hepatocytes (BNL Cl.2, ATCC No.: TIB73) were grown in DMEM containing $10 \%$ fetal calf serum (FCS), $100 \mathrm{U} / \mathrm{ml}$ penicillin, $10 \mu \mathrm{g} / \mathrm{ml}$ streptomycin, and $2 \mathrm{mM}$ glutamine in $3 \mathrm{~cm}$ culture dishes on coverslips $\left(5 \times 10^{4}\right.$ cells/dish).

For transfection, $6 \mu \mathrm{g}$ pCMV- $\beta$-gal in $160 \mu \mathrm{l} \mathrm{HBS}$ were complexed with $12 \mu \mathrm{g}$ of hTfpL (for HeLa cells) or $8 \mu \mathrm{g} \mathrm{mTfpL} 290$ (for mouse hepatocytes) in $160 \mu \mathrm{l} \mathrm{HBS}$ and incubated for 30 minutes at room temperature. In another experiment $6 \mu \mathrm{g}$ pCMV- $\beta$-gal were complexed with $6 \mu \mathrm{g}$ of TfpL in a volume of $200 \mu \mathrm{l} \mathrm{HBS}$ for 30 minutes at room temperature. Thereafter, $10 \mu \mathrm{g}$ of the fusogenic peptide InflupL in $100 \mu \mathrm{l} \mathrm{HBS}$ were added to the mixture and incubated for a further 30 minutes. Ternary complexes consisting of transglutaminase-mediated polylysine-modified adenovirus were formed as described above.

These polycation-DNA complexes were then mixed with $1 \mathrm{ml}$ DMEM containing $2 \%$ FCS, antibiotics, and glutamine and added to the cells. To demonstrate the effect of chloroquine and free adenovirus on transfection efficiency, chloroquine to a final concentration of $100 \mu \mathrm{M}$ or $50 \mu \mathrm{l}$ of virus stock solution dl312 was added. After an incubation period of 4 hours at $37^{\circ} \mathrm{C}$ the medium was removed and the cells were cultured for 48 hours in $3 \mathrm{ml}$ of fresh DMEM containing $10 \%$ FCS, antibiotics, and glutamine.

For histochemical detection of $\beta$-galactosidase expression, the cells were washed once with phosphate-buffered saline solution (PBS) and fixed with $0.5 \%$ glutaraldehyde in PBS for 5 minutes at room temperature. Then the fixative was removed and the cells were washed once with PBS followed by incubation with the staining solution containing $10 \mathrm{mM}$ phosphate buffer $\mathrm{pH} 7.0,150 \mathrm{mM} \mathrm{NaCl}, 1 \mathrm{mM} \mathrm{MgCl} 2,3.3$ $\mathrm{mM} \mathrm{K}_{4} \mathrm{Fe}(\mathrm{CN})_{6} 3 \mathrm{H}_{2} 0,3.3 \mathrm{mM} \mathrm{K}_{3} \mathrm{Fe}(\mathrm{CN})_{6}$, and $0.2 \%$ 5-bromo-4-chloro-3-indolyl-betagalactopyranosid at $37^{\circ} \mathrm{C}$ for 20 minutes to 3 hours. ${ }^{26}$ Thereafter, the coverslips were rinsed in PBS, water, and $96 \%$ ethanol and mounted in Mowiol ${ }^{\circledR}$ on slides.

\section{RESULTS AND DISCUSSION}

\section{From Transferrinfection to Transfection with Transferrin-Containing Ternary DNA Complexes}

Eukaryotic cells contain many different kinds of receptors for the transport of macromolecules across the cell membrane. These receptors not only are numerous (there are, for instance, $10^{5}$ to $5 \times 10^{5}$ asialoglycoprotein receptors ${ }^{29}$ on hepatocytes), but also have exceedingly high internalization rates. Asialoglycoprotein receptors are calculated to internalize as many as 200 ligands each ${ }^{27}$ per day (or ca. 500 ligands per second per cell). This compares to an internalization rate for transferrin of about 300 ligands per second per cell. ${ }^{28}$ If we succeed in pirating these 
mechanisms for the introduction of DNA into cells, we can expect to obtain a procedure that is not only highly efficient, but also physiological. Wu and Wu were first to show that DNA can be combined with a receptor ligand by the expedient means of covalently linking a polylysine tail to the ligand. ${ }^{8.9}$ The polylysine binds DNA ionically. Unexpectedly, we found that complexes formed from transferrinpolylysine conjugates and circular plasmid DNA form distinct molecular condensates in the shape of virus-like "donuts" with a diameter of about $80 \mathrm{~nm}$ (FIG. 3A), whereas linear DNA also yields some donuts, but in the main cigar-shaped structures such as those indicated by the arrow in FIGURE 3A. The number of DNA molecules per donut is not known, but we find that the overall shape and size do not vary noticeably when circular DNA in the range of 5,000-50,000 base pairs is used. Such donuts can be calculated to contain as many as 100 transferrin molecules attached per DNA molecule via the polylysine moiety. Despite the structural modifications that must ensue from the conjugation with polylysine and the binding of DNA, the association of transferrin with the transferrin receptor is little impaired ${ }^{10}$ and the physiology of the cell appears to be unaffected as far as the capacity to transport iron is concerned. ${ }^{9}$ Indeed, cells can be subjected to repeated transferrinfection without loss of viability. ${ }^{10}$

To visualize the importance of transferrin-polylysine/DNA conjugates, chicken HD3 cells were incubated with transferrin (conalbumin)-free differentiation me$\operatorname{dium}^{10}$ at $37^{\circ} \mathrm{C}$ for 18 hours. After the addition of transferrin-polylysine DNA conjugate (labeled with fluoresceinisothiocyanate [FITC] at the polylysine moiety), cells were incubated for 2 hours. FIGURE 3B shows the fluorescence of FITC. In FIGURE 3C, the DNA contents of the cells were fluorescently labeled with DAPI. FITC labeling is distributed over the vesicular system of the cell and the cell membrane, whereas DAPI staining reveals the DNA in both the cell nucleus as well as the vesicular system.

In the normal course of events one would expect DNA complexes to become targeted to the lysosomal compartment and to be degraded therein. The inclusion of chloroquine is a possible remedy because DNA is released into the cytoplasm as a consequence of vacuolarization and disruption of the endosome (see introductory paragraphs), but the behavior of the various cell types is idiosyncratic in that some cell types do not respond to chloroquine. A more general means to liberate the DNA from the vesicular system is the inclusion of adenovirus during transferrinfection ${ }^{14}$ with an additional improvement arising from physically linking the virus to the transferrin-polylysine conjugate. ${ }^{17.18}$

\section{Linkage between DNA Condensates and Adenovirus Greatly Enhances Luciferase Reporter Gene Expression}

Physical linkage between adenovirus strain d 312 and polylysine can be brought about by either incubating the two components with transglutaminase or biotinylating the adenovirus and streptavidinylation of the polylysine. The effect of linkage on transfection efficiency is clearly demonstrated in FIGURE 4 where hepatocytes were incubated with transferrin-polylysine/DNA complexes (TfpL) in the presence of chloroquine or in the presence of adenovirus (AdenoV $+\mathrm{TfpL}$ ). Transfection in the presence of adenovirus is elevated, showing the typical enhancement of the transport of transferrin-polylysine DNA complexes into the cells. ${ }^{14}$ In pLAdenoV/TfpL, polylysine was attached to adenovirus by means of transglutaminase. The complex was reacted with DNA, neutralizing part of the negative charges of the DNA, and later transferrin-polylysine was added to neutralize the remainder of the charges. In 

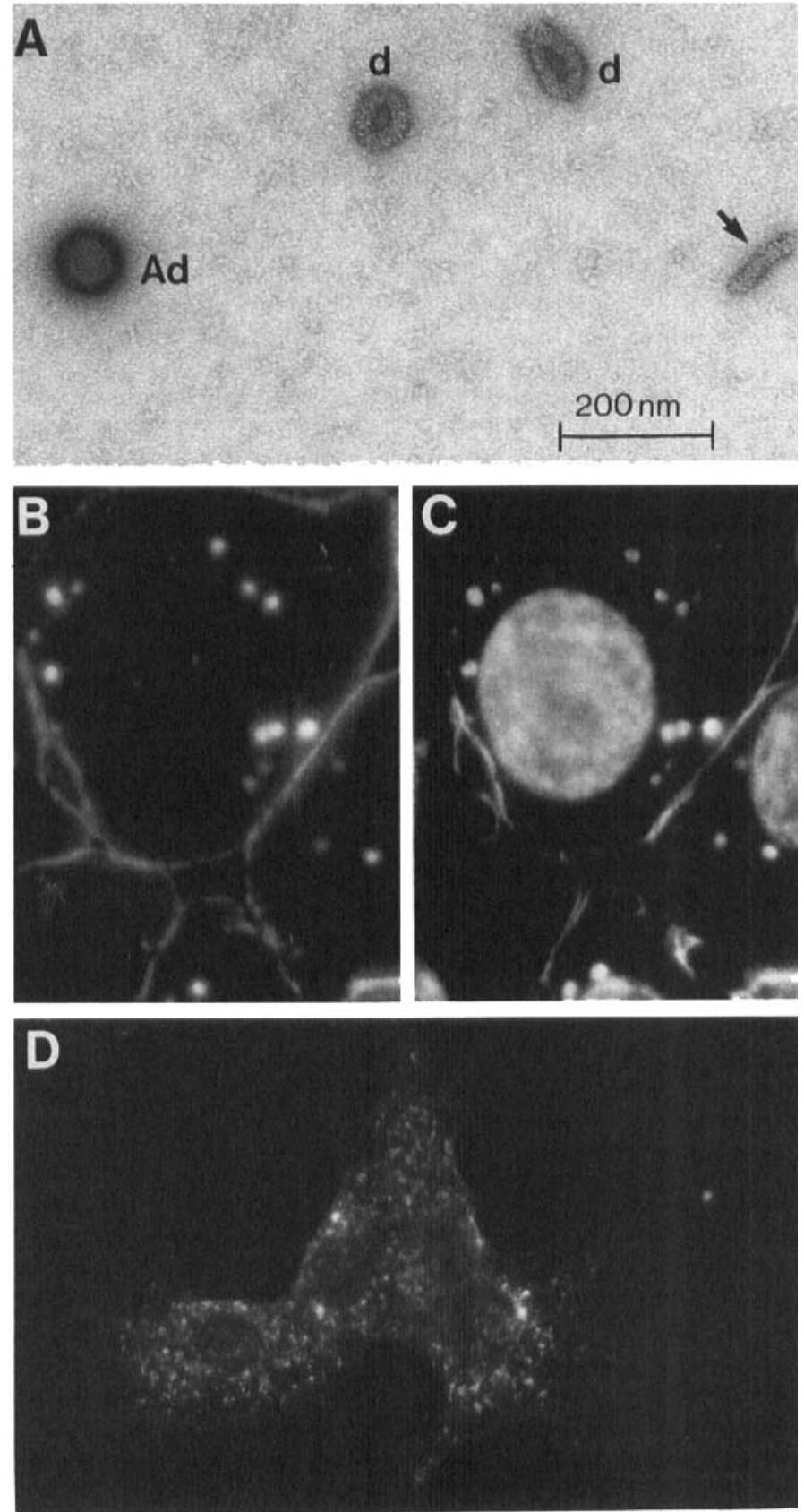

FIGURE 3. 


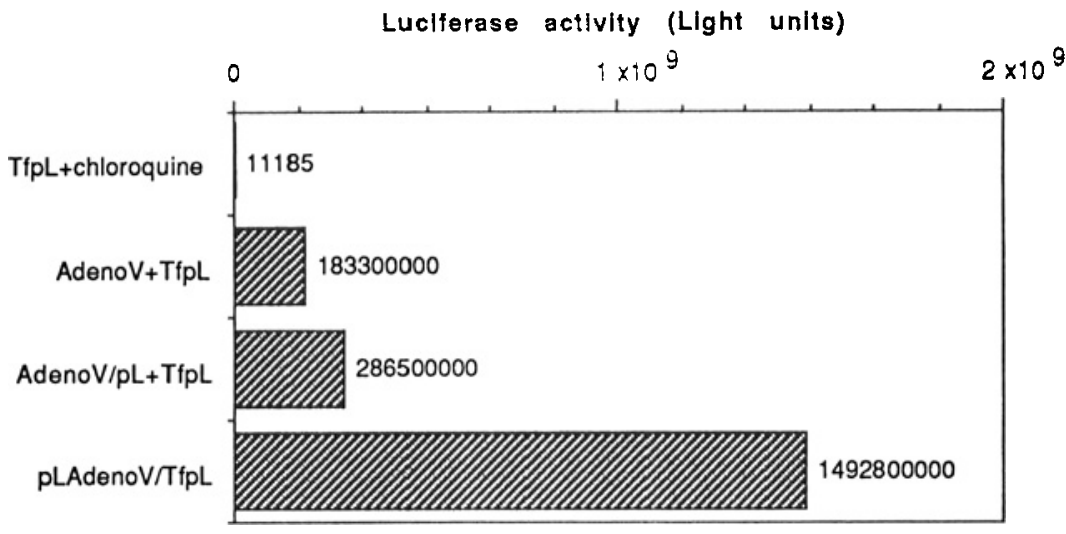

FIGURE 4. Effect of enzymatically polylysine-modified adenovirus on transfection efficiency in mouse hepatocytes. Six $\mu g$ of pCMV-L was complexed to adenovirus that had been covalently modified with polylysine by transglutaminase (d1312/TG-pL). Full condensation of the DNA was achieved by the addition of $\mathrm{mTfpL} 290$. To demonstrate the specific effect of transglutaminase, transfection was performed in parallel with an adenovirus preparation in which the enzyme was omitted during the coupling reaction $(\mathrm{d} / 312 / \mathrm{pL})$. For comparison, DNA was directly complexed to $\mathrm{mTfpL} 290$, and transfections were performed either with the addition of free adenovirus (dl312) or in the presence of $100 \mu \mathrm{M}$ chloroquine.

this way a ternary complex of adenovirus-polylysine/transferrin-polylysine DNA was synthesized. As can be seen, an extraordinarily high value of $1.5 \times 10^{9}$ luciferase light units was obtained. In slot AdenoV $+\mathrm{pL}+\mathrm{TfpL}$, adenovirus and $\mathrm{pL}$ were mixed as for $\mathrm{pLAdenoV} / \mathrm{TfpL}$, but transglutaminase treatment was omitted. TfpL was then added. Transfection is of the order of AdenoV + TfpL, because colocalization of virus and TfpL/DNA complexes in the endosome is a stochastic process in contrast to $\mathrm{pLAdenoV} / \mathrm{TfpL}$ where, through linkage of $\mathrm{pL}$ and AdenoV, colocalization is assured, yielding a very high level of transferrinfection (5,000 light units per cell).

A similar point is also made in FIGURE 5 where biotinylated virus and streptavidinylated polylysine was used to link the two components. The figure further demonstrates that complexes with physically linked viruses also work in a highly diluted state, whereas experiments with free, unlinked virus require high concentrations of both virus and transferrin-polylysine/DNA complexes. In the experiments reported in FIGURE 5, $6 \mu \mathrm{g}$ of covalently circular plasmid DNA CMV-L were combined with the proteinacious moicties indicated in the figure legend. A series of 10 -fold dilutions

FIGURE 3. (A) Electromicrograph of transferrin-polylysine/DNA complexes and of added adenovirus. Negative stain. Arrow points to a cigar-shaped complex that is typical for the polylysine-transferrin conjugated with linear DN $A$. The "donut" structure of covalantly circular DNA complexes is clearly seen (d). Ad denotes adenovirus. (B and C) Fluorescent micrographs of HD3 cells. (B) FITC-labeled polylysine in polylysine-transferrin/DNA complex. (C) DAPI fluorescent stain of DNA (see text). Magnification $\times 1250$. (D) Demonstration of uptake of biotinylated DNA complexed to TfpL in hepatocytes (Hep G2). Transfection was performed in the presence of $100 \mu \mathrm{M}$ chloroquine for 4 hours. Endocytosed DNA was visualized with phycoerythrin-coupled streptavidin. Note the uniform uptake of DNA/TfpL. complexes over the whole cell population. Magnification $\times 510$. 

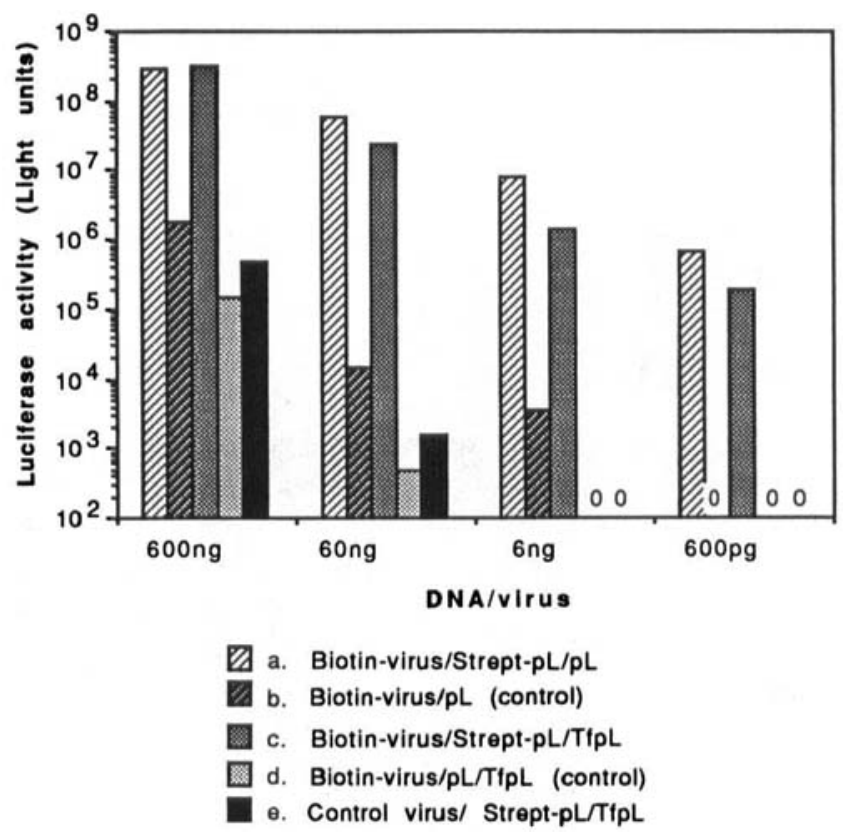

FIGURE 5. Impact of linking adenovirus with polylysine-transferrin/DNA complexes on transfection efficiency. Six $\mu \mathrm{g}$ of covalently circular CMV-L plasmid were combined with various conjugates and diluted to yield the final DNA amounts denoted at the bottom of the graph. (a) Biotin-virus/Strept-pL/pL is a binary complex in which $800 \mathrm{ng}$ streptavidinylated polylysine were mixed with $40 \mu \mathrm{l}$ biotinylated virus and $6 \mu \mathrm{g}$ plasmid DNA and then $3 \mu \mathrm{g}$ polylysine $(\mathrm{pL})$ were added to saturate the charges of the DNA. (b) Biotin-virus/pL (control) is the control for the a construct in which $4 \mu \mathrm{g}$ polylysine were added to $6 \mu \mathrm{g}$ plasmid DNA and biotinylated virus. Because polylysine is not streptavidinylated in this case, polylysine forms "donuts" with DNA that are not linked to the virus. (c) Biotin-virus/Strept-pL/TfpL is the same as the biotin-virus/Strept-pL/pL except that $9 \mu \mathrm{g}$ polylysine-transferrin conjugates were added to the initial binary complex consisting of $6 \mu \mathrm{g}$ plasmid and $800 \mathrm{ng}$ streptavidinylated polylysine and biotinylated virus. This yields a combi-complex capable of binding to both transferrin and viral receptors on the cell, revealing the capacity of linked virus to enhance transferrinfection. (d) Biotin-virus/pL/TfpL (control) is the control for the construct in which transferrin-polylysine conjugates are not linked to virus, because polylysine has not been streptavidinylated. This is an example of enhancement of transferrinfection with free virus. (e) Control virus/Strept-pL/TfpL is another control for construct c. Eight hundred ng Strept-pL were incubated with unmodified virus followed by the addition of polylysine-transferrin conjugate. Formation of polylysine-transferrin "donuts" is expected, whereas because of the unmodified nature of the virus, there is no formation of a ternary complex.

were then made down to $600 \mathrm{pg}$ DNA per $6 \mathrm{~cm}$ diameter tissue culture dish (ca. $3 \times 10^{5}$ HeLa cells).

From inspection of the figure it becomes clear that where the adenovirus is not physically linked with the DNA condensate as in slot biotin-virus/pL (control), biotin-virus/pL/TfpL, or control virus/Strept-pL/TfpL, luciferase expression is low even at high DNA input, and these compositions were all very highly sensitive to dilution. In these experiments the adenovirus can only enhance transfection if by 
chance it colocalizes in the same endosome, and this is only guaranteed at high concentration of both virus and DNA condensate.

For biotin-virus/Strept-pL/pL and biotin-virus/Strept-pL/TfpL, which represent binary and ternary DNA condensate, respectively, in which the virus is physically linked with the DNA via a biotin-streptavidin bridge, very high levels of gene expression are obtained $\left(4 \times 10^{8}\right.$ light units per $3 \times 10^{5} \mathrm{HeLa}$ cells at $600 \mathrm{ng}$ DNA per dish) and the expression remains high even after a 1,000-fold dilution of the complexes. For the last point (600 pg DNA per dish) there were only 300 DNA copies and 1 virus per cell and still $8 \times 10^{5}$ light units were obtained. This contrasts with the calcium phosphate precipitation transfection procedure in which modest numbers of luciferase light units are obtained at an input of $5 \times 10^{5}$ DNA molecules per cell. ${ }^{29}$ Clearly, the linked virus constructs are a most efficient means for introducing DNA into cells, because colocalization of DNA condensate, virus and/or transferrin is guaranteed.

One striking feature of these HeLa cell transfection experiments is that both binary complexes consisting solely of virus and linked polylysine (supplemented with free polylysine to reach electroneutrality) and the ternary complex containing transferrin-polylysine transfect cells at a similar level and that there is no synergism between transferrin- and adenovirus-receptors. We suggest that this may be a consequence of $\mathrm{HeLa}$ cells having a relatively large number of adenovirus receptors and relatively few transferrin receptors, so that in both binary and ternary complexes it is actually the adenovirus receptor and not so much the transferrin receptor that transports DNA.

This situation contrasts with that of $\mathrm{K} 562$ cells. Figure 6 demonstrates, first, that a high level of Iuciferase activity was obtained in K562 cells in the presence of chloroquine (but in the absence of adenovirus) for reasons that were already discussed. The addition solely of polylysine-transferrin/DNA, in the absence of chloroquine, yielded background levels of luciferase activity, whereas the simultaneous addition of both transferrin-polylysine conjugate and free virus yielded

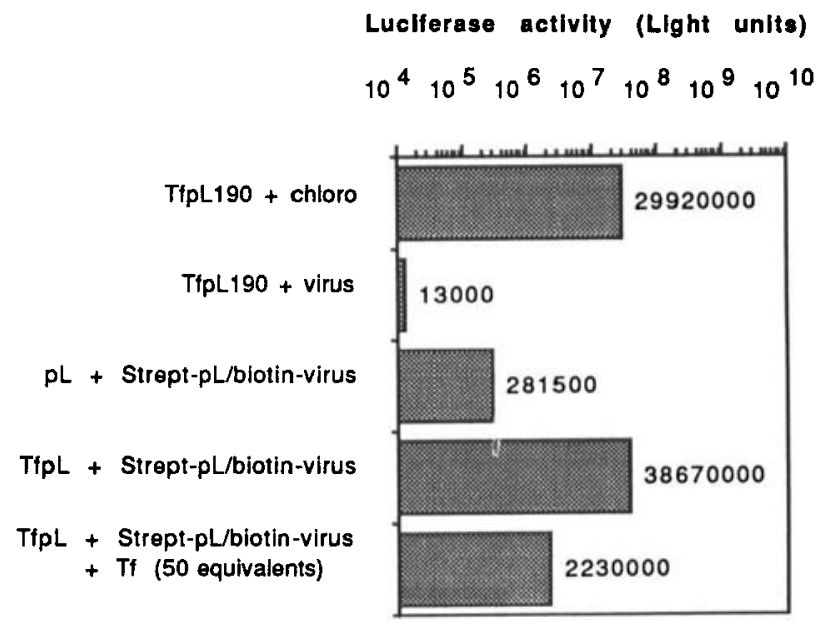

FIGURE 6. Influence of chloroquine and adenovirus on transferrinfection of K562 cells (see text). 

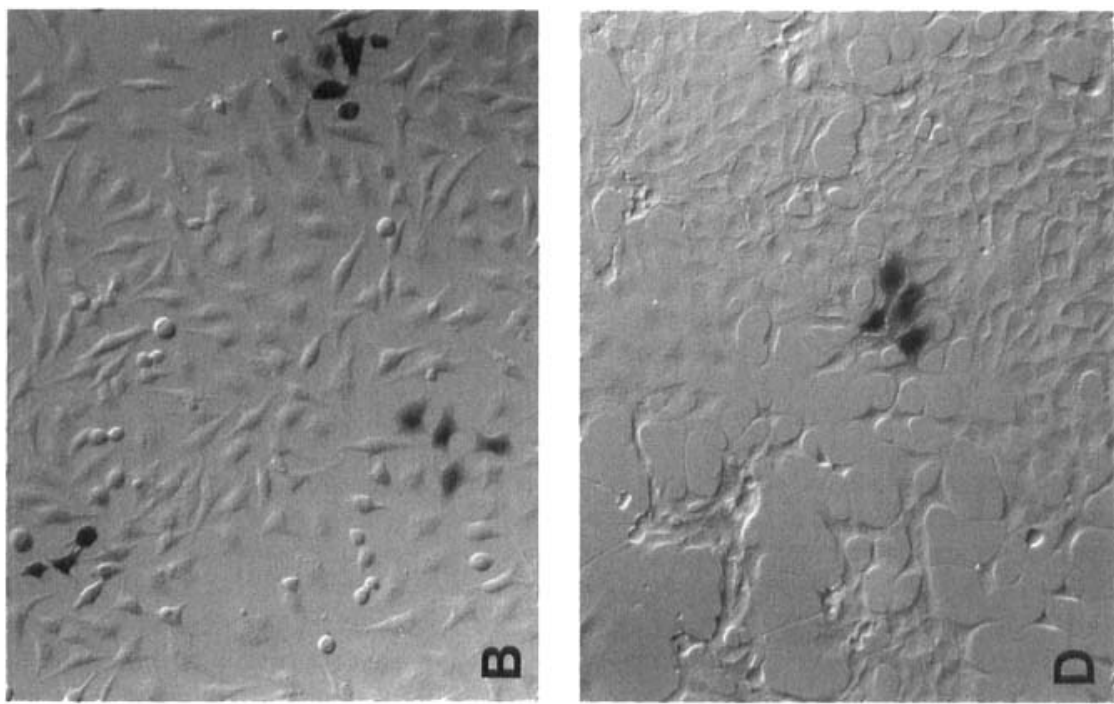

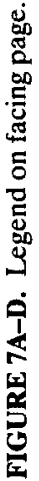
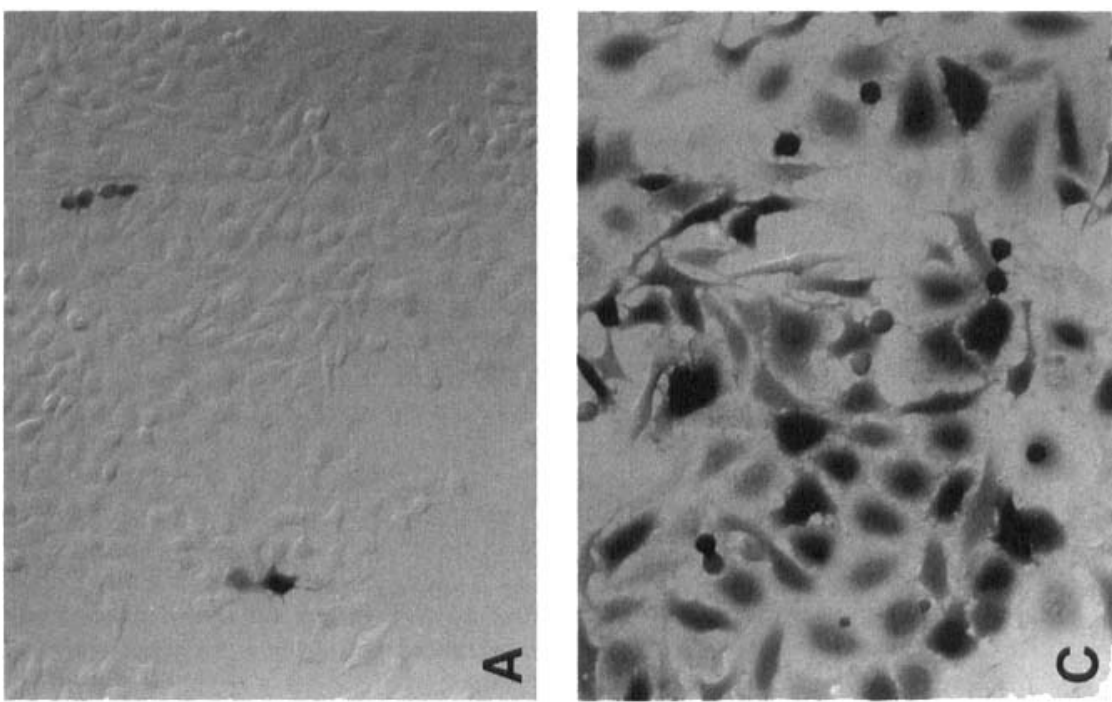


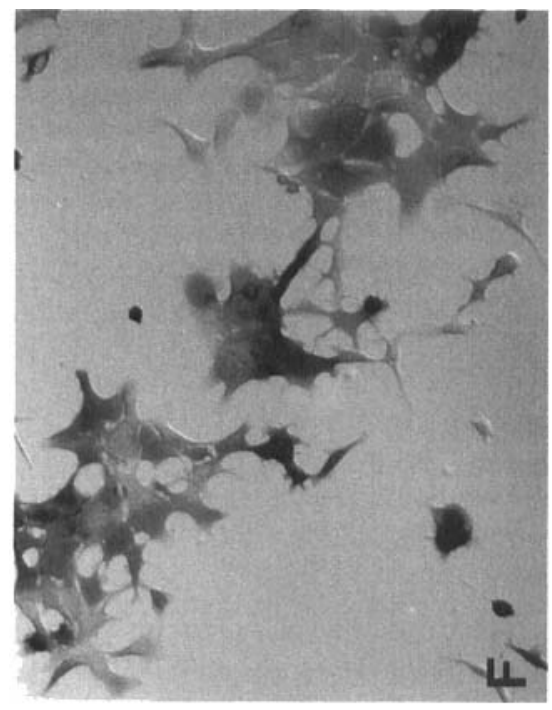

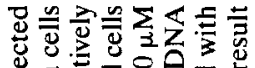

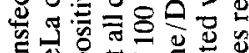

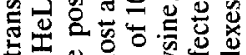

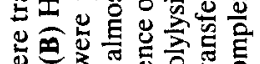

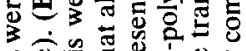

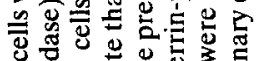

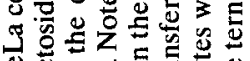

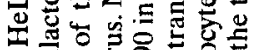

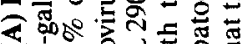
ड़े 离可可运了品

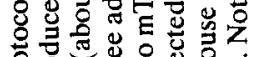

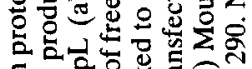

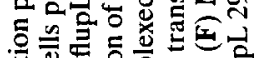

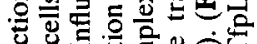

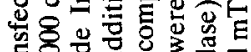

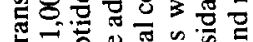

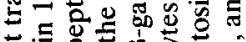

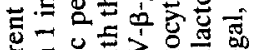

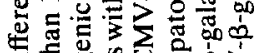
동 ×.

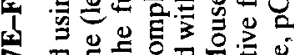

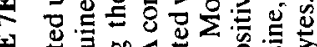

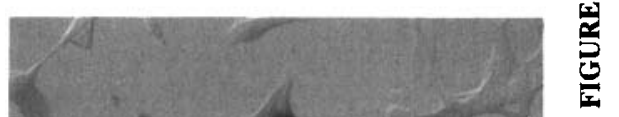
吉

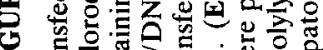

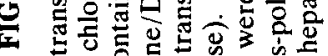

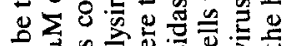
1

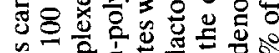

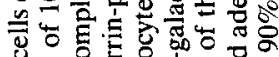

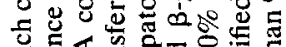

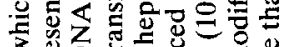

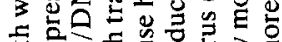

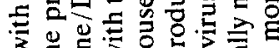

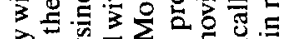

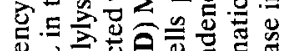

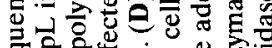

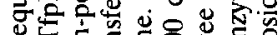

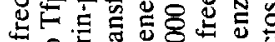

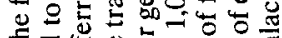

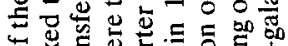

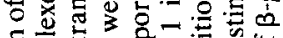

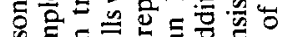

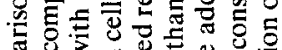

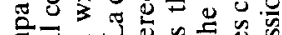

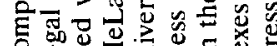

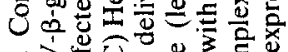

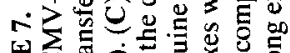

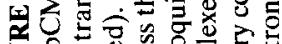

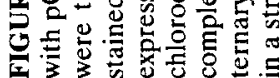


relatively few light units; even when the virus was linked to polylysine in a binary complex, only moderate levels of luciferase activity were obtained. By contrast, the ternary complexes containing transferrin increased luciferase expression to nearly $4 \times 10^{7}$ light units, presumably because here the transferrin receptor, which abounds on K562 cells, comes into play. This contention is supported by our finding that the addition of $\mathbf{5 0}$ mass equivalents of transferrin lowers transferrinfection by ternary complexes by a factor of about 18 due to the competition between free transferrin and ternary complexes for the same receptors.

\section{The Fusogenic Peptide of Influenza Virus Can Partially Replace the Function of the Linked Adenovirus}

The fusogenic peptide domain(s) of the viruses which enter via endocytosis are thought to change their conformation upon acidification of the endosomal milieu and to expose hydrophobic domains that initiate lysis of the endosomal membrane ${ }^{13}$ and allow entry of the virus into the cytoplasm. If the function of the physically linked or free virus during transferrinfection is to disrupt the endosome, then it should be possible to obtain a similar endosomolytic property for a fusogenic peptide when such a peptide is included in a complex containing DNA, transferrin, and polylysine.

Hemagglutinin HA2 of the influenza virus contains such a fusogenic peptide. ${ }^{20}$ The peptide from the $\mathrm{NH}_{2}$-terminus of $\mathrm{HA} 2,23$ amino acids long, was synthesized and coupled to polylysine (see Materials and Methods). As we shall show, combicomplexes consisting of DNA, transferrin-polylysine, and fusogenic peptidepolylysine conjugates facilitate transferrinfection (FIG. 7B), although not at the level of free adenoviruses in excess (FIG. 7C) or linked adenovirus (FIG. 7F).

\section{Efficiency of Reporter Gene Expression at the Cellular Level}

In FIgURE 7 the frequency with which cells in a cell population became transferrinfected is shown as a consequence of using different transfection protocols. FIGURE 7A-C depicts expression of the $\beta$-galactosidase reporter gene in HeLa cells, FIGURE 7D-F that in mouse hepatocytes.

Transferrinfection with human transferrin-polylysine/DNA complex plus chloroquine yielded less than 1:1,000 of treated HeLa cells that expressed the reporter gene. Positive cells occurred in clusters of two or four cells, presumably because galactosidase-positive cells have divided once or twice. In FigURE 7B HeLa cells were transfected with DNA to which transferrin-polylysine had been added to neutralize a fraction of the DNA charges. The remainder of the negative charges were then neutralized by the addition of influenza virus fusogenic peptide-polylysine conjugate to yield a ternary complex consisting of transferrin-polylysine/fusogenic peptide-polylysine/DNA. This ternary complex allowed expression of the reporter gene in about $2 \%$ of cells. Note the typical grouping of positive cells. In FIGURE 7C HeLa cells were transfected with the classical transferrin-polylysine/DNA complexes in the presence of free, replication-defective d1312 adenovirus. Virtually all the cells respond to this transfection protocol.

FIGURE 7D-F shows that mouse hepatocytes are somewhat more refractory to transferrinfection. The reporter gene complexed with murine transferrin-polylysine was applied in the presence of chloroquine. Less than 1:1,000 cells became positive for $\beta$-galactosidase (FIG. 7D). The low probability of obtaining gene expression has 
to be compared with the high efficiency with which cells in a culture take up the transferrin-polylysine/DNA complexes (FIG. 3D). The same protocol, but in the presence of free adenovirus, yielded about $10 \%$ positive cells (FIG. 7E). This number can be increased to nearly $100 \%$ by using adenovirus at high multiplicity, which, however, is rather toxic for the cells (unpublished results). Virtually all cells expressed $\beta$-galactosidase when the ternary combi-complex consisting of transferrinpolylysine/adenovirus-polylysine/DNA (containing linked adenovirus) was used (FIG. 7F).

\section{Stable Transfection of Tissue Culture Cells}

Although adenovirus-enhanced transferrinfection excels by the high level of gene expression that is obtained transiently (see below), so far the technique has been less

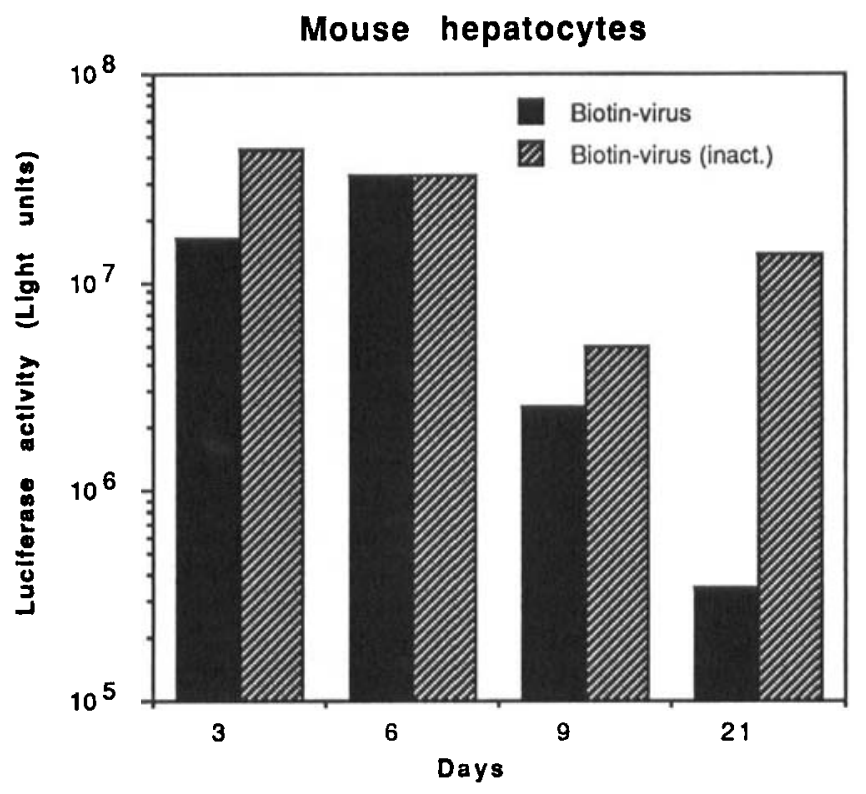

FIGURE 8. Time course of luciferase reporter gene expression in a transferrinfected embryonic hepatocyte cell line. The use of psoralene inactivated adenovirus ${ }^{16}$ prolongs a high level of reported gene expression (see text).

useful for the production of stably transformed cell lines. The reason for this is that many cells that express the inserted gene (having experienced adenovirus-enhanced transferrinfection) stopped dividing and often round up and detach from the support, making clonal selection more difficult. Such behavior is not seen when the fusogenic peptide is used. At the moment it is unclear if these deleterious effects seen when using adenovirus are caused by residual viral gene activity in adeno strain dI312 or if they are ascribable to the intense endosomolytic property of the virus. 


\section{DNA Reporter Genes Are Expressed Transiently but for a Protracted Period}

$\mathrm{K} 562$ cells, as discussed, can be transfected at a very high level by inclusion of chloroquine, and these cells were shown to express the $\beta$-galactosidase gene transiently for at least 10 days. ${ }^{6}$ We wanted to know if adenovirus-enhanced transferrinfected cells also express the transfected reporter gene (luciferase) transiently but for a relatively long time. For this we used the adherent embryonic hepatocyte cell line BNL Cl.2 and transferrinfected it with ternary complexes amounting to 200 viruses per cell. We know from parallel experiments that at high viral input $(2,000$ viruses per cell) $<95 \%$ of the hepatocytes become transfected. As can be seen in FigURE 8 , hepatocytes express luciferase to levels of $4 \times 10^{8}$ light units. High expression prevails at least 21 days, especially when the virus is inactivated by psoralene treatment. ${ }^{16}$

\section{Efficient Transfer of Cosmids into Tissue Culture Cells}

When viral vectors, such as retroviruses or adenoviruses, are used to infect celis, there is a severe limitation as to the size of the DNA that can be inserted into the viral genome. When the virus is used as an endosomolytic principle, the DNA is deposited on the outside of the intact virus, as for instance in the ternary complexes consisting of transferrin-polylysine/virus-polylysine/DNA or in the binary complexes consisting of virus-polylysine/polylysine/DNA, and here limitations as to the size of the DNA to be transferred are less obvious. Thus, we find that we can transfer $48-\mathrm{kb}$ cosmids with similar efficiency as plasmids of 6 and $15 \mathrm{~kb}$ using binary and ternary complexes. ${ }^{16}$ We are presently investigating whether yeast artificial chromosomes (YACs) can be inserted into cells using transferrinfection protocols.

\section{REFERENCES}

1. VAn Der Krol, A. R., J. N. M. Mol \& A. R. StutTJE. 1988. Antisense genes in plants: An overview. Gene 72: 45-50.

2. Powell, P. A., D. M. Stark, P. R. Sanders \& R. N. Beachy. 1989. Protection against tobacco mosaic virus in transgenic plants that express tobacco mosaic virus antisense RNA. Proc. Natl. Acad. Sci. USA 86: 6949-6952.

3. Mol, J. N. M., A. R. Van Der Krol, A. J. Van Tunen, R. Van Blokland, P. De Lange \& A. R. STUITJE. 1990. Regulation of plant gene expression by antisense RNA. FEBS 268: $427-430$.

4. Day, A. G., E. R. Bejarano, K. W. Buck, M. Burrell \& C. P. Lichtenstein. 1991. Expression of an antisense viral gene in transgenic tobacco confers resistance to the DNA virus tomato golden mosaic virus. Proc. Natl. Acad. Sci. USA 88: 6721-6725.

5. Stout, J. T. \& C. T. CASKeY. 1990. Antisense RNA Inhibition of HPRT synthesis. Somatic Cell Mol. Gen. 16: 369-382.

6. Cotten, M., E. Wagner \& M. L. Birnstiel. 1992. Receptor mediated transport of DNA into eukaryotic cells. In Methods in Enzymology. R. Wu, ed. Academic Press. New York. In press.

7. WU, G. Y. \& C. H. WU. 1987. Receptor-mediated in vitro gene transformation by a soluble DNA carrier system. J. Biol. Chem. 262: 4429-4432.

8. WU, G. Y. \& C. H. WU. 1988. Receptor-mediated gene delivery and expression in vivo. J. Biol. Chem. 263: 14621-14624.

9. Wagner, E., M. Zenke, M. Cotten, H. Beug \& M. L. Birnstiel. 1990. Transferrinpolycation conjugates as carriers for DNA uptake into cell. Proc. Natl. Acad. Sci. USA 87: $3410-3414$. 
10. Zenke, M., P. Steinlein, E. Wagner, M. Cotten, H. Beug \& M. L. Birnstiel. 1990. Receptor-mediated endocytosis of transferrin-polycation conjugates: An efficient way to introduce DNA into hematopoietic cells. Proc. Natl. Acad. Sci. USA 87: 3655-3659.

11. Cotten, M., F. Längle-Rouault, H. Kirlappos, E. Wagner, K. Mechtler, M. Zenke, H. BEUG \& M. L. BIRNSTIEL. 1990. Transferrin-polycation-mediated introduction of DNA into human leukemic cells: Stimulation by agents that affect the survival of transfected DNA or modulate transferrin receptor levels. Proc. Natl. Acad. Sci. USA 87: 4033-4037.

12. Sipe, D. M., A. Jesurum \& R. F. MurPhy. 1991. Absence of $\mathrm{Na}^{+}, \mathrm{K}^{+}$-ATPase regulation of endosomal acidification in K562 erythroleukemia cells. J. Biol. Chem. 266: 34693474.

13. Pastan, I., P. Seth, D. Fitzgerald \& M. Willingham. 1986. In Virus Attachment and Entry into Cells. eds.: 141-146. R. L. Crowell \& K. Lonberg-Holm, eds. Am. Soc. Microbiol., Washington.

14. Curiel, D. T., S. Agarwal, E. Wagner \& M. CotTen. 1991. Adenovirus enhancement of transferrin-polylysine-mediated gene delivery. Proc. Natl. Acad. Sci. USA 88: 88508854.

15. JONES, N. \& T. SHENK. 1979. An adenovirus type 5 early gene function regulates expression of other early viral genes. Proc. Natl. Acad. Sci. USA 76: 3665-3669.

16. Cotten, M., E. Wagner, K. Zatloukal, S. Philipps, D. T. Curiel \& M. L. Birnstiel. 1992. High efficiency receptor-mediated delivery of small and large (48kb) gene constructs using the endosome disruption activity of defective or chemically-inactivated adenovirus particles. Proc. Natl. Acad. Sci. USA 89: 6094-6098.

17. Curiel, D. T., E. Wagner, M. Cotten, M. L. Birnstiel, Ch. Li, St. Loechel, S. Agarwal \& P. Hu. 1992. High efficiency gene transfer by adenovirus coupled to DNA-polylysine complexes via an antibody bridge. Human Gene Therapy 3: 147-154.

18. Wagner, E., K. Zatloukal, M. Cotten, H. Kirlappos, K. Mechtler, D. T. Curiel \& M. L. BIRNSTIEL. 1992. Coupling of adenovirus to polylysine-DNA complexes greatly enhances receptor mediated gene delivery and expression of transfected genes. Proc. Natl. Acad. Sci. USA 89: 6099-6113.

19. FolK, J. E. \& S. I. CHUNG. 1985. Transglutaminases. Methods Enzymol. 113: 358-375.

20. Wagner, E., M. Cotten, K. Zatloukal \& M. L. Birnstiel. 1992. Influenza virus hemagglutinin $\mathrm{HA}-2 \mathrm{NH}_{2}$-terminal fusogenic peptides augment gene transfer by transferrin-polylysine/DNA complexes: Towards a synthetic virus-like gene transfer vehicle. Proc. Natl. Acad. Sci. USA, in press.

21. Wharton, S. A., S. R. Martin, R. W. H. Ruigrok, J. J. Skehel \& D. C. Wiley. 1988. Membrane fusion by peptide analogues of influenza virus haemagglutinin. J. Gen. Virol. 69: 1847-1857.

22. Atherton, E., M. J. Gait, R. C. Sheppard \& B. J. Williams. 1979. The polyamide method of solid phase peptide and oligonucleotide synthesis. Bioorganic Chem. 8: 351370.

23. Atherton, E. \& R. C. Sheppard. 1989. Solid phase peptide synthesis. The Practical Approach Series. IRL Press. Oxford, England.

24. Davidson, D. \& J. A. Hassell. 1987. Overproduction of polyoma middle T antigen in mammalian cells through the use of an adenovirus vector. J. Virol. 61: 1226-1239.

25. Chardonnet, Y. \& S. Dales. 1970. Early events in the interaction of adenoviruses with HeLa cells. I. Penetration of type 5 and intracellular release of the DNA genome. J. Virol. 40: $462-477$.

26. Lim, K. \& CH.-B. Chat. 1989. A simple assay for DNA transfection by incubation of the cells in culture dishes with substrates for $\beta$-galactosidase. BioTechniques 7: 576-579.

27. SPIESS, M. 1990. The asialoglycoprotein receptor. A model for endocytic transport receptors. Biochemistry 29: 10009-10017.

28. STRYER, L. 1988. In Biochemistry, 3rd ed., W. H. Freeman. New York, NY.

29. Sambrook, J., E. F. Fritsch \& T. Maniatis. 1989. Molecular Cloning III. Cold Spring Harbor Laboratory Press. New York. 